\title{
Phenotypic diversity and selection maintain Leishmania amazonensis infectivity in BALB/c mouse model
}

\author{
Benoît Espiau $^{1,2}$, Virginia Vilhena ${ }^{3,4}$, Armelle Cuvillier ${ }^{1,5}$, Aldina Barral ${ }^{3,6}{ }^{+}$, Gilles Merlin ${ }^{1,6}$ \\ ${ }^{1}$ Université de Bordeaux, Laboratoire de Génomique Fonctionnelle des Trypanosomatidés, Bordeaux, France \\ ${ }^{2}$ LabEx Corail, Papetoai, Moorea, Polynésie Française ${ }^{3}$ Fundação Oswaldo Cruz, \\ Instituto Gonçalo Moniz, Salvador, BA, Brasil ${ }^{4}$ Faculdade Anhanguera de Brasília, Brasília, DF, Brasil \\ ${ }^{5}$ B Cell Design, Limoges, France ${ }^{6}$ Instituto de Investigação em Imunologia, Salvador, BA, Brasil
}

Leishmania are protozoan parasites that show remarkable diversity, as revealed by the various clinical forms of leishmaniasis, which can range from mild skin lesions to severe metastatic cutaneous/mucosal lesions. The exact nature and extent of Leishmania phenotypic diversity in establishing infection is not fully understood. In order to try to understand some aspects of this diversity, we subcutaneously infected BALB/c mice with first and second generation subclones of a L. amazonensis strain isolated from a patient (BA125) and examined in vivo lesion growth rate and antimony susceptibility. In vivo fast-, medium- and slow-growing subclones were obtained; moreover, fast-growing subclones could generate slow-growing subclones and inversely, revealing the continuous generation of diversity after passage into mice. No antimony-resistant subclone appeared, probably a rare occurrence. By tagging subclone cells with a L. amazonensis genomic cosmid library, we found that only a very small number of founding cells could produce lesions. Leishmania clones transfected with in vivo selected individual cosmids were also diverse in terms of lesion growth rate, revealing the cosmid-independent intrinsic characteristics of each clone. Our results suggest that only a few of the infecting parasites are able to grow and produce lesions; later, within the cell mixture of each lesion, there coexist several parasite populations with different potentialities to grow lesions during the next infection round. This may reflect a sort of programmed heterogeneity of individual parasites, favoring the survival of some individuals in various environmental conditions.

Key words: Leishmania amazonensis - subcloning - phenotypic diversity - infectivity - selection

Leishmania are digenetic protozoan parasites of the Trypanosomatidae family that are responsible for severe diseases in tropical and subtropical countries. Discovered more than a century ago, the parasites exist in two forms: the amastigotes that live inside parasitophorous vacuoles of mammalian macrophages, and the promastigotes that live extracellularly in the lumen of the digestive tract of phlebotomine sandflies.

There are different forms of leishmaniasis, and Leishmania cells appear to develop in vitro resistance to most drugs relatively easily under selection. Several studies have shown that isolates and strains of these parasites are heterogeneous and polymorphic in the wild and in the laboratory, in terms of pathogenicity and genomic organisation. It is still difficult to associate virulence/host immune response/clinical form of the disease to particular genomic characteristics (Greenblatt et al. 1990, Kahl et

doi: 10.1590/0074-02760160280

Financial support: CNRS, Université de Bordeaux 2, Région Aquitaine, CAPES-COFECUB, UFBA, FIOCRUZ. VV was a recipient of a $\mathrm{PhD}$ fellowship from the Brazilian Government; $\mathrm{AC}$ was a recipient of a post-doctoral Lavoisier fellowship; $\mathrm{AB}$ is a CNPq senior investigator; and GM is a retired CNRS senior investigator.

$\mathrm{BE}$ and $\mathrm{VV}$ contributed equally to this work.

+ Corresponding author: aldinabarral@gmail.com

Received 24 June 2016

Accepted 14 September 2016 al. 1990, Almeida et al. 1996, Noyes et al. 1997, Cupolillo et al. 1998, El Tai et al. 2001, Schonian et al. 2001, Victoir $\&$ Dujardin 2002). To further complicate the situation, the same parasite strain does not cause the same disease in different strains of mice (Kahl et al. 1990, Martinez et al. 1991, Sinagra et al. 1997, Sulahian et al. 1997, Sakthianandeswaren et al. 2009). Differences have even been described between isolates of the same patient (Cuervo et al. 2004) or clones of the same Leishmania species, as cloning of a virulent strain could generate virulent and avirulent clones (Handman et al. 1983, Garin et al. 2001). Diversity in virulence among clones of a metastatic $L$. guyanensis strain (Martinez et al. 2000) and in antimony susceptibility among isolates from patients and clones recovered from these isolates (Moreira et al. 1998, Carrio et al. 2000, Pal et al. 2001) have been described. Moreover, isolates from antimony unresponsive patients have been shown to contain a mixture of susceptible and resistant clones (Bhattacharyya et al. 2002).

With the aim to study Leishmania phenotypic diversity, we chose an in vivo infection animal model, simplified compared to natural infections, but with the advantages of some parameter constancy. Our model consisted in an infectious strain of L. amazonensis isolated from a patient (BA125), the BALB/c mouse strain, and the footpad infection. Two criteria of clinically relevant potential diversity were examined, i.e., in vivo lesion growth rate and antimony susceptibility. We minimised and standardised as much as possible the unavoidable in vitro culture steps, as they are known to introduce uncontrollable effects on the infectivity stability. First, cells extracted 
from a parental lesion were subcloned and individual subclones used for new infections in mice treated or not with antimony; the cells of some of the obtained lesions were again subcloned as for the first sets. Then the parental strain was transfected with a L. amazonensis cosmid genomic library, mice infected with the transfectants, and the cosmids recovered from the lesion cells. Lesion growth kinetics, phenotype stability and cosmid occurrence in recovered lesion amastigotes were compared.

Leishmania infectivity depends upon multigenic determinants (Chang et al. 2003) and the precise cause of its loss or persistence is not really understood. The purpose of this report is not to address this complex question, but to describe in more detail a biological phenomenon of interest and propose an interpretation. We hypothesize that (i) among the cells used for infection, only a few are able to grow and produce lesions and (ii) different cells with different potentialities to grow lesions during the next infection round coexist in the cell mixture of each lesion.

\section{MATERIALS AND METHODS}

Parasite culture - The strains used in this study were L. amazonensis MHOM/BR/1987/BA125 (BA125) and MHOM/BR/1987/BA276 (BA276). Promastigotes were cultured as described previously (Cuvillier et al. 2000) at $24^{\circ} \mathrm{C}$ in $\mathrm{AM}$ medium, i.e. RPMI- 1640 medium plus 25 $\mathrm{mM}$ Hepes $\mathrm{pH}$ 7.5, $2 \mathrm{mM}$ glutamine, $2 \mathrm{mg} / \mathrm{mL}$ dextrose, 1 $\mathrm{mM}$ sodium pyruvate, 1x MEM essential and non-essential amino acids, 50 units $/ \mathrm{mL}$ penicillin, $50 \mu \mathrm{g} / \mathrm{mL}$ streptomycin, and 8\% FCS (all ingredients were purchased from Eurobio) in closed flasks under gentle agitation. The cells were passaged every two-three days in order to keep the cell density between $4 \times 10^{6}$ and $1.5 \times 10^{7}$ cells per $\mathrm{mL}$.

L. amazonensis subcloning - Promastigotes were subcloned by using two different methods. Method I: exponentially growing cells were diluted to a density of $10^{3}$ cells per $\mathrm{mL} ; 0.5-\mu \mathrm{L}$ drops of the suspension were loaded into 96-well microtiter plates and carefully inspected visually under an inverted microscope (ocular 10X, lens 40X); only wells containing a single live promastigote were supplemented with additional $100 \mu \mathrm{L}$ AM medium; microtiter plates were then incubated at $24^{\circ} \mathrm{C}$ with $\mathrm{CO} 2$; subclones (about one out of 10 drops) were cultured until they reached the number required for making stabilates and infecting mice (about 6-7 weeks). Method II: $0.5 \mathrm{~mL}$ of exponentially growing cells, diluted to $20-50$ cells per $\mathrm{mL}$, were spread onto $10-\mathrm{cm}$ Petri dishes containing $0.7 \%$ SeaPlaque agarose (low-melting, BMA) in AM medium; dishes were pre-dried for $1 \mathrm{~h}$ under a sterile hood, caps off, and subsequently incubated for $2-3$ weeks at $24^{\circ} \mathrm{C}$ with $\mathrm{CO}$; when colonies became visible by eye, they were transferred to 96 -well microtiter plates containing $100 \mu \mathrm{L}$ AM medium and further cultivated as in Method I.

Experimental infection of mice and antimony treatment - L. amazonensis stationary phase promastigotes (five days after last passage, density of 1.5 to $1.8 \times 10^{7}$ cells per $\mathrm{mL}$ ) were harvested, washed twice with phosphate-buffered saline (PBS), counted and resuspended in PBS at $5 \times 10^{8}$ cells per mL; $5 \times 10^{6}$ cells (i.e. $10 \mu \mathrm{L}$ ) were injected subcutaneously into the hind footpads of five-week-old female Balb/cJRj mice (Centre d'Elevage Robert Janvier). Antimony-treated mice were i.p. injected every day following infection, for two weeks, with 0.1 mL Glucantime ${ }^{\mathrm{TM}}$ (Specia). Footpad size was monitored once every week using a caliper. Each mouse was tagged with distinctive ink marks for individual recognition.

Recovery of Leishmania cells from lesions - When lesions reached 8 to $10 \mathrm{~mm}$ diameter, mice were sacrificed; the infected footpads were cut off, plunged into ethanol for $10 \mathrm{~min}$; then, lesions were macerated in PBS, cell aggregates homogenised in a Thomas potter, and debris eliminated by low-speed centrifugation; amastigotes remaining in the supernatant were washed twice with PBS and further dissociated by repeated passages through 1 -mL syringes with $23 \mathrm{G} / 26 \mathrm{G}$ needles. Amastigotes were counted, transferred to AM medium at $2-5 \times 10^{6}$ cells per $\mathrm{mL}$ and incubated at $24^{\circ} \mathrm{C} .48 \mathrm{~h}$ later, newly differentiated promastigotes were cloned as described above.

Subclone tagging with a cosmid library of L. amazonensis - We used the previously described genomic L. amazonensis BA276 DNA cosmid library (Lachaud et al. 2014) to tag the Leishmania clones; this library was constructed with the pcosTL vector, which confers G-418 resistance (Kelly et al. 1994), and propagated in the Escherichia coli STBL-2 ${ }^{\mathrm{TM}}$ strain (Invitrogen); it contains about 20,000 independent 50-kb insert clones, representing more than 15 haploid genome copies. 2,500 individual clones were kept at $-80^{\circ} \mathrm{C}$ in 96 -well microtiter plates in LB medium plus $50 \%$ glycerol. Cosmid DNA was extracted from bacteria by using the Triton X-100 method (Ausubel et al. 1989). For cosmid DNA extraction from Leishmania amastigotes or promastigotes, $10^{8-9}$ cells were washed twice with PBS, resuspended in $0.5 \mathrm{~mL} 10 \mathrm{mM}$ Tris- $\mathrm{HCl} \mathrm{pH} \mathrm{7.5,} 0.25 \mathrm{mM} \mathrm{NaCl}$, lysed by addition of $4.5 \mathrm{~mL} 10 \mathrm{mM}$ Tris- $\mathrm{HCl} \mathrm{pH} 8,10 \mathrm{mM}$ EDTA, $10 \mathrm{mM} \mathrm{NaCl}, 0.5 \%$ SDS, and incubated for $2 \mathrm{~h}$ at $50^{\circ} \mathrm{C}$ with $0.5 \mathrm{mg}$ Proteinase $\mathrm{K}$; after two phenol/chloroform extractions, the DNA was ethanol precipitated, recovered with a Pasteur pipette, dissolved in $4 \mathrm{~mL}$ TE buffer (10 mM Tris-HCl, $1 \mathrm{mM}$ EDTA), incubated with $0.1 \mathrm{mg}$ RNAse A for $2 \mathrm{~h}$ at $37^{\circ} \mathrm{C}$, re-extracted twice with phenol/chloroform, ethanol precipitated, washed twice and recovered in $0.5 \mathrm{~mL}$ sterile TE buffer.

For Leishmania transformation, cosmid-containing bacterial clones were individually grown in $300 \mu \mathrm{L} \mathrm{LB}$ medium; about 400 cultures were then pooled and the cosmid DNA extracted. Each DNA pool was electroporated into L. amazonensis BA125 promastigotes $(50 \mu \mathrm{g}$ DNA, $10^{8}$ cells in $250 \mu \mathrm{L}, 450 \mathrm{~V}, 74 \Omega, 600 \mu \mathrm{F}, 2-\mathrm{mm}$ cuvettes) derived from footpad lesion amastigotes that were extracted $48 \mathrm{~h}$ before the electroporation. Transfected Leishmania cells were immediately spread onto $0.7 \%$ agarose plates containing AM medium plus $10 \mu \mathrm{g} /$ mL G-418 (Cuvillier et al. 2000). Isolated Leishmania colonies were then picked and further grown individually. 400 transformed, five-day stationary phase Leishmania clones were then pooled and injected into the hind footpads of 6-12 BALB/c mice ( $10^{6}$ cells/footpad). Half of the mice were treated with Glucantime ${ }^{\mathrm{TM}}$ as described above and lesion growth monitored every week. Amas- 
tigotes were recovered from individual lesions. Cosmid DNA was extracted from amastigotes and $100 \mathrm{ng}$ electroporated into $50 \mu \mathrm{L}$ electrocompetent $E$. coli STBL$2^{\mathrm{TM}}$ bacteria ( $1600 \mathrm{~V}, 192 \Omega, 40 \mu \mathrm{F}, 1-\mathrm{mm}$ cuvettes). Transformed bacterial colonies were picked and the cosmids they contained identified by Sal I restriction band pattern on $0.7 \%$ agarose gels.

\section{RESULTS}

Cloning the L. amazonensis BA125 strain - This strain was isolated from a patient in 1987 and has since been grown in vitro and passaged into BALB/c mice for an undetermined number of times. Two months after an experimental infection, amastigotes were recovered from a 1-cm footpad lesion; $48 \mathrm{~h}$ later, newly differentiated promastigotes were subcloned using Method I or II (see Materials and methods). Groups of six BALB/c mice were infected in both hind footpads with stationary phase cells of one of fifteen randomly selected subclones or the parental line BA125. Three of the six mice were treated with antimony. The evolution of the lesion size was monitored during the following weeks.

Fig. 1 shows the results obtained with a set of subclones isolated using Method I. Growth kinetics in un-

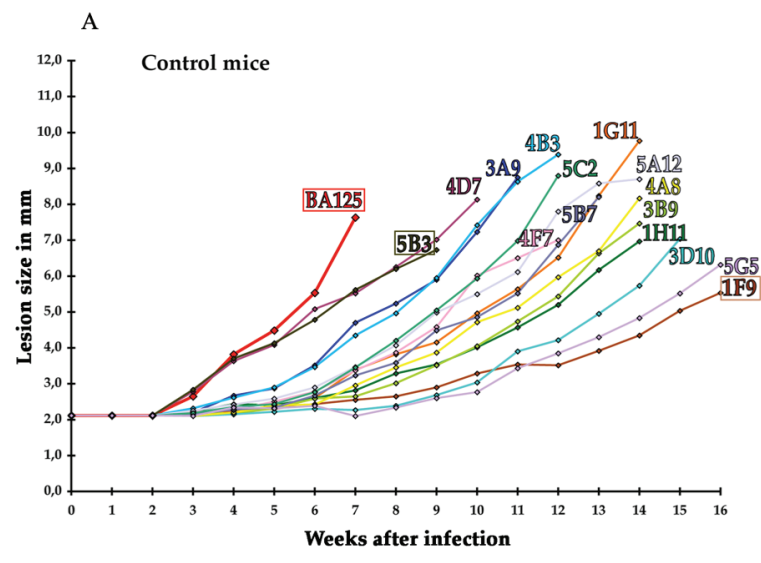

B

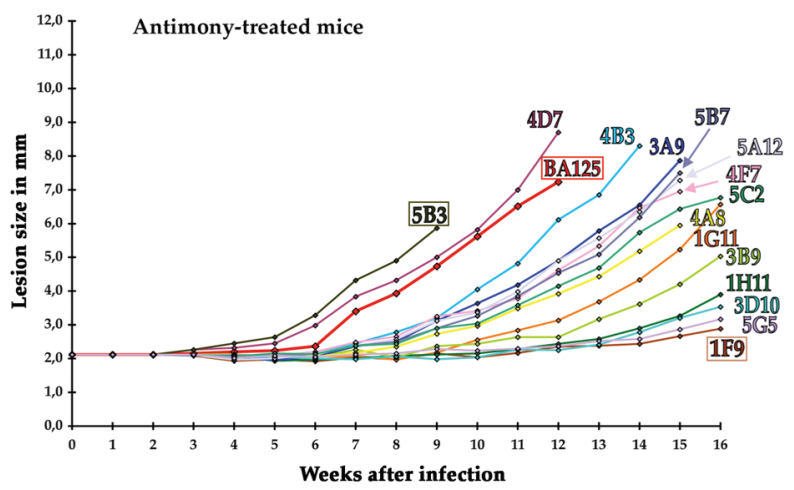

Fig. 1: growth kinetics of lesions generated by the parental BA125 strain of Leishmania amazonensis and its subclones. (A) Control mice; (B) antimony-treated mice (daily injections for the first two weeks after infection). Each group contained three mice, and both hind footpads of each mouse were infected; data are the mean value of the six footpad sizes. For clarity, the standard deviation (15-20\%) is not indicated. Uninfected footpads kept a value of $2 \mathrm{~mm}$ during the time of the experiment (not shown). Mice were sacrificed when the lesions reached 8-10 mm.
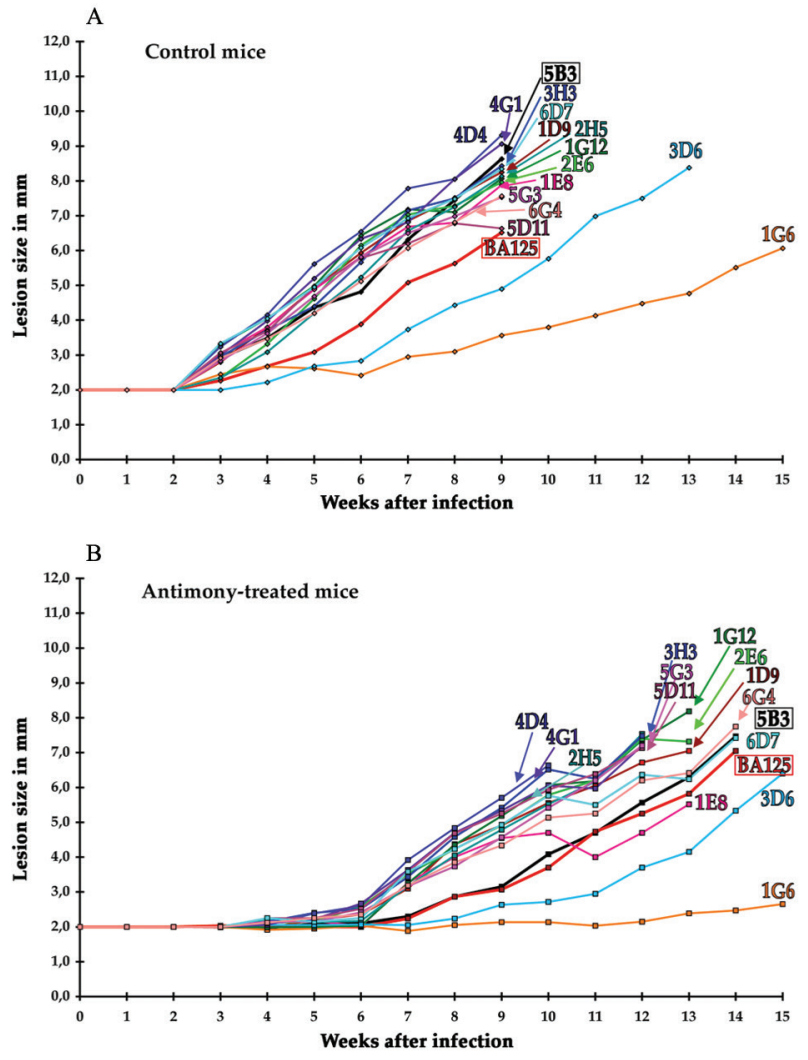

Fig. 2: lesion growth kinetics for subclones of a first generation fastgrowing subclone (5B3 of Fig. 1). (A) Control mice; (B) antimonytreated mice. Red: parental BA125 strain.

treated mice revealed the existence of fast-growing (e.g., 5B3), slow-growing (e.g., 1F9) and intermediate (e.g., 1G11) subclones (Fig. 1A). Although there was some diversity in lesion sizes, the standard deviation was usually less than $15 \%$ within a group. Thus, out of fifteen subclones, four grew very fast (5B3, 4D7, 3A9, 4B3), three rather slowly (3D10, 5G5, 1F9), and the others displayed an intermediate rate. In antimony-treated mice (Fig. 1B), lesion growth was uniformly slowed: the fastest subclones $(5 \mathrm{~B} 3,4 \mathrm{D} 7)$ were still the fastest to grow; the slowgrowing ones grew even slower (1F9, 5G5). The only effect of antimony treatment was to slow lesion growth.

Similar results were obtained with another set of fifteen subclones using cloning Method II. In both cases, however, no antimony-resistant subclone was found.

Thus, the cell population found in a lesion appeared heterogeneous in its capacity to grow lesion.

Subcloning a fast- and slow-growing first generation subclone - The stability of the phenotypes was investigated. Amastigotes from a single lesion developed by a fastgrowing first generation subclone (5B3 of Fig. 1) were extracted, left to differentiate to promastigotes for $48 \mathrm{~h}$, and subcloned by Method I or II. Then, groups of BALB/c mice were infected as above with these second generation subclones, and lesion growth monitored (Fig. 2). Twelve out of fourteen second generation subclones were fastgrowing, like the parental first generation subclone 5B3, 




B



Fig. 3: lesion growth kinetics for subclones of a first generation slow-growing subclone (1F9 of Fig. 1). (A) Control mice; (B) antimony-treated mice. Red: parental BA125 strain.

while two (3D6 and 1G6) were slow-growing (Fig. 2A, untreated mice). As previously (Fig. 1B), the antimony treatment only delayed growth for a few weeks (Fig. 2B). This experiment was repeated with another set of second generation subclones issued from another fast-growing first generation subclone; the same results were obtained (not shown). Thus, like the parental BA125 strain, a lesion generated by a fast-growing first generation subclone contained heterogeneous cells, at least regarding the growth rate of the lesion, as slow-growing cells were produced.

The next question was: what happens with slowgrowing subclones? Cells from a lesion generated by a slow-growing first generation subclone (1F9 of Fig. 1) were extracted, subcloned and used for footpad infection as above (Fig. 3). Most second generation subclones grew relatively slowly, like the parental subclone $1 \mathrm{~F}$, and slower than the parental BA125 strain, except subclone $2 \mathrm{C} 7$ which grew as fast as the parental BA125 strain (Fig. 3A, untreated mice). This "reversion" occurred at a relatively high frequency (1/12). Concerning the antimony treatment (Fig. 3B) no resistant subclone was found; again, lesion growth rates were slowed, particularly for second generation subclones $2 \mathrm{C} 7$ and 1E2 which appeared hypersusceptible to antimony.

Thus, we observed the generation of diverse phenotypes with regard to lesion growth rate each time $L$. amazonensis BA125 parasites were passaged into mice.
Antimony resistance was not found within our subclone library and may require a more continuous in vivo selection. The cell populations appeared as mixtures of phenotypically different cells and the phenotypes did not seem stable within a subclone. To confirm this, we attempted to trace the subclones within lesions.

Restricted subclone diversity of L. amazonensis cells within lesions - Tagging can be performed by using either a vector or a cosmid strategy. We first considered tagging the subclones by transfecting the parasites with a library of random non-coding DNA sequences inserted into the pTEX vector, which confers G-418 resistance (Kelly et al. 1992). However, the DNA extracted from L. amazonensis BA125 cells transfected with an empty pTEX plasmid was unable to transform bacteria (probably because the small episomes formed very large concatenates that could not enter the bacteria) (Kelly et al. 1992); with such strategy, it would have been impossible to analyse the episomes found in lesion amastigotes.

On the other hand, the DNA recovered from pcosTL (Kelly et al. 1994)-based cosmid-transfected Leishmania cells (that were G418-resistant) led to successful transformation of bacteria and DNA analysis of the recovered cosmids by Sal I restriction band pattern. Since a genomic DNA library of the L. amazonensis BA276 strain in cosmid pcosTL was available (Lachaud et al. 2014), 
TABLE I

The different types of cosmids found in a Leishmania pool before and after passage in mice

\begin{tabular}{|c|c|c|c|c|c|c|c|c|}
\hline \multirow[b]{3}{*}{ Cosmid types } & \multirow[b]{3}{*}{ Extracted from promastigotes ${ }^{1}$} & \multicolumn{7}{|c|}{ Extracted from lesion amastigotes from antimony-treated mice } \\
\hline & & \multicolumn{6}{|c|}{ Number of occurrences in 24 bacterial clones } & \multirow[b]{2}{*}{$\begin{array}{c}\text { Total out of } 144 \\
\text { clones }\end{array}$} \\
\hline & & $\begin{array}{c}\text { Mouse } \\
1\end{array}$ & $\begin{array}{c}\text { Mouse } \\
2\end{array}$ & $\begin{array}{c}\text { Mouse } \\
3\end{array}$ & $\begin{array}{c}\text { Mouse } \\
4\end{array}$ & $\begin{array}{c}\text { Mouse } \\
5\end{array}$ & $\begin{array}{c}\text { Mouse } \\
6\end{array}$ & \\
\hline 2 types (unnamed) & 5 & 0 & 0 & 0 & 0 & 0 & 0 & 0 \\
\hline $\mathrm{T} 42$ & 4 & 0 & 0 & 0 & 1 & 0 & 2 & 3 \\
\hline T35 & 3 & 0 & 0 & 1 & 3 & 0 & 1 & 5 \\
\hline 2 types (unnamed) & 3 & 0 & 0 & 0 & 0 & 0 & 0 & 0 \\
\hline T26 & 2 & 16 & 11 & 5 & 13 & 1 & 6 & 52 \\
\hline T36 & 2 & 0 & 0 & 1 & 0 & 0 & 0 & 1 \\
\hline T37 & 2 & 0 & 0 & 0 & 1 & 0 & 0 & 1 \\
\hline 6 types (unnamed) & 2 & 0 & 0 & 0 & 0 & 0 & 0 & 0 \\
\hline 21 types (unnamed) & 1 & 0 & 0 & 0 & 0 & 0 & 0 & 0 \\
\hline $\mathrm{T} 27$ & 0 & 1 & 0 & 0 & 0 & 0 & 0 & 1 \\
\hline T28 & 0 & 1 & 0 & 0 & 0 & 0 & 0 & 1 \\
\hline T29 & 0 & 1 & 0 & 0 & 0 & 0 & 0 & 1 \\
\hline T30 & 0 & 3 & 11 & 3 & 0 & 0 & 5 & 22 \\
\hline T31 & 0 & 1 & 0 & 0 & 0 & 0 & 0 & 1 \\
\hline T32 & 0 & 1 & 0 & 0 & 0 & 0 & 0 & 1 \\
\hline T33 & 0 & 0 & 1 & 13 & 0 & 8 & 0 & 22 \\
\hline T34 & 0 & 0 & 1 & 0 & 0 & 0 & 0 & 1 \\
\hline T38 & 0 & 0 & 0 & 0 & 2 & 0 & 0 & 2 \\
\hline T39 & 0 & 0 & 0 & 0 & 2 & 0 & 0 & 2 \\
\hline $\mathrm{T} 40$ & 0 & 0 & 0 & 0 & 0 & 0 & 4 & 4 \\
\hline T41 & 0 & 0 & 0 & 0 & 0 & 0 & 1 & 1 \\
\hline $\mathrm{T} 43$ & 0 & 0 & 0 & 0 & 0 & 0 & 1 & 1 \\
\hline $\mathrm{T} 44$ & 0 & 0 & 0 & 0 & 0 & 2 & 3 & 5 \\
\hline $\mathrm{T} 45$ & 0 & 0 & 0 & 0 & 0 & 0 & 1 & 1 \\
\hline Unidentified & 0 & 0 & 0 & 1 & 2 & 13 & 0 & 16 \\
\hline Total types & & 7 & 4 & 5 & 6 & 3 & 9 & 20 \\
\hline
\end{tabular}

${ }^{1}$ : extracted from Leishmania pool promastigotes just before mice infection. Number of occurrences in 71 bacterial clones.

we decided to use the cosmid strategy for the Leishmania clone tagging attempts.

In a first experiment, 384 individually grown bacterial cosmid clone cultures were pooled, the cosmids extracted and used to transform freshly differentiated $L$. amazonensis BA125 promastigotes. After selection of the transformants on agarose plates with G-418, 414 colonies were picked, individually grown, pooled and one million cells injected into hind footpads of six BALB/c mice. Two months later, when lesions had developed, cosmids were extracted from lesion amastigotes, reintroduced into E. coli, and cosmid DNA from 24 bacterial colonies analysed by Sal I restriction digestion for each of the six mice. To control the cosmid diversity of the transformed Leishmania pool, cosmids were also extracted from an aliquot, just before mice infection, and analysed. Before infection, 36 cosmid types were found out of 71 bacterial colonies, of which 21 were represented once, nine twice, three thrice, meaning that the expected diversity of cosmids was somehow respected (Table I). After infection, only three-nine cosmid types per mouse could be found out of 24 bacterial clones; besides, a few cosmid types were over-represented and common to several mice: cosmid T26 (36\% of bacterial clones), cosmid T30 (15\%), and cosmid T33 (15\%). Remarkably, these cosmids were under-represented in the 71 bacterial colonies analysed before passage in mice: T26 was found only twice (3\%), and cosmids T30 and T33 were not found at all. Thus, passage in mice led to an enrichment of a small number of cosmids.

Involvement of intrinsic factors for in vivo selection - In another experiment, lesion amastigotes from antimony-treated mice were recovered and their cosmid content analysed (Table II). As previously, after $48 \mathrm{~h}$ a limited number of cosmid types were found: T3 (40\%), T5 (30\%), T8 and T9 (8\%), plus several less represented ones (T11 and T15, 2\% each) (Table II, column A). Inter- 
TABLE II

Cosmid diversity in in vitro culture

\begin{tabular}{|c|c|c|c|}
\hline \multirow[b]{3}{*}{ Cosmid types } & \multicolumn{3}{|c|}{ Among bacterial clones (\%) } \\
\hline & A & $\mathrm{B}$ & $\mathrm{C}$ \\
\hline & $48 \mathrm{~h}$ after extraction from lesion ${ }^{a}$ & Two months in culture ${ }^{b}$ & Four months in culture ${ }^{c}$ \\
\hline $\mathrm{T} 1$ & 2 & 0 & 0 \\
\hline $\mathrm{T} 2$ & 2 & 0 & 0 \\
\hline T3 & 40 & 25 & 0 \\
\hline $\mathrm{T} 4$ & 0 & 4 & 0 \\
\hline T5 & 30 & 22 & 0 \\
\hline T6 & 4 & 0 & 0 \\
\hline $\mathrm{T} 7$ & 2 & 0 & 0 \\
\hline $\mathrm{T} 8$ & 8 & 0 & 0 \\
\hline T9 & 8 & 4 & 0 \\
\hline $\mathrm{T} 10$ & 0 & 4 & 0 \\
\hline $\mathrm{T} 11$ & 2 & 0 & 0 \\
\hline $\mathrm{T} 15$ & 2 & 41 & 100 \\
\hline
\end{tabular}

$a$ : 48 bacterial clones analysed; $b: 24$ bacterial clones analysed; $c: 24$ bacterial clones analysed.

estingly, we also observed a loss of diversity during in vitro growth of the derived promastigotes: two months after seeding, cosmid T15 became predominant (41\%) while T5 and T3 diminished (22 and 25\% resp.), and four months later, there was $100 \%$ cosmid T15.

The 50-kb genomic fragments of the cosmids could code for approximatively 10 genes each, and these genes could influence the in vivo selection, as they were probably expressed in the transfectant cells. To test this, four cosmids (T3, T5, T8 and T15), chosen for their different abundance in lesions, were transfected individually into freshly prepared promastigotes. Three independent colonies transfected by each cosmid were isolated on agarose plates, grown, injected into mice footpads, and the lesion growth monitored with and without antimony treatment (data not shown). Considering cosmid T3 for example, colony T3-1 grew lesions very slowly (similar to subclone 1F9 of Fig. 1), colony T3-3 grew lesions very fast (similar to subclone 5B3 of Fig. 1) and colony T3-2 was intermediate (similar to subclone 1G11 of Fig. 1), and all three were susceptible to antimony. Similar results were obtained with the other cosmids (T5, T8 and T15). In conclusion, different subclones transfected with the same cosmid displayed different phenotypes. At least in these experiments, the phenotypes reflected intrinsic properties of the subclones and were not cosmid-dependent.

Evolution of pools of clones - 16 mice were infected with a mixture of equal amounts of three very different subclones, T5-1 (fast lesion growth), T3-1 (slow lesion growth) and T15-4 (no detectable lesion after six months); half were treated with antimony, the other half left untreated. Cosmids were isolated from mature lesions of individual mice as previously. As shown in Table III, for control mice, cosmid T5 (of subclone T5-1, the fast growing one) represented $80-90 \%$ of the recovered cosmids, cosmid T3 (of subclone T3-1, the slow growing one), 10-20\% and T15 (of subclone T15-4, the non-growing one), $0 \%$. There were only slight variations from mouse to mouse and antimony treatment only slowed lesion growth without changing the proportions of the recovered plasmids.

In all, with regard to lesion growth, the L. amazonensis strain used consisted in a mixture of different cells, some able to develop lesions rapidly, some less rapidly. Whether this feature is reversible or not is not known; we only observed the presence of a minority of slow-growing cells in lesions that developed rapidly, and a minority of fast-growing cells in lesions that developed slowly. This diversity seemed to be recreated after each passage in mice. Only the cells originating from a few founding ones were present in the lesions. A similar restriction of diversity could be observed in in vitro culture. Whether this can be generalised or not to other Leishmania strains or species is unknown. Exploring these phenomena might prove useful for the study and understanding of Leishmania biology.

\section{DISCUSSION}

In this work, we studied the infectivity of freshly isolated L. amazonensis clones and subclones from mouse footpad lesions. Regarding lesion growth rate, the cloned parasites were heterogeneous, as some grew faster than others. Such heterogeneity in the cell population of a strain that has been passaged in mice for years was somehow surprising, as one could have expected the non-infectious cells to have been eliminated. In fact, heterogeneity was found within subclones after each passage in mice. Besides, only a very small number of founding infecting parasites appeared responsible for lesion development. 
TABLE III

In vivo outcome of mixtures of defined clones

\begin{tabular}{|c|c|c|c|c|c|c|c|}
\hline \multirow{2}{*}{ Leishmania clones used for infection } & \multirow[b]{2}{*}{ Mouse treatment } & \multirow[b]{2}{*}{ Mouse \# } & \multicolumn{5}{|c|}{$\begin{array}{l}\text { Cosmids recovered from lesions } \\
\text { (number of bacterial clones) }\end{array}$} \\
\hline & & & $\mathrm{T} 3$ & $\mathrm{~T} 5$ & $\mathrm{~T} 15$ & $?$ & Total \\
\hline \multirow{16}{*}{$\begin{array}{l}\text { Equal amounts of T3-1 (slow growth), } \\
\text { T5-1 (fast growth) and T15-4 (no lesion after six months) }\end{array}$} & \multirow{8}{*}{ Untreated } & 1 & 3 & 20 & 0 & 1 & 24 \\
\hline & & 2 & 3 & 21 & 0 & 0 & 24 \\
\hline & & 3 & 8 & 15 & 0 & 1 & 24 \\
\hline & & 4 & 5 & 19 & 0 & 0 & 24 \\
\hline & & 9 & 0 & 23 & 0 & 1 & 24 \\
\hline & & 10 & 1 & 22 & 0 & 1 & 24 \\
\hline & & 11 & 2 & 22 & 0 & 0 & 24 \\
\hline & & 12 & 2 & 22 & 0 & 0 & 24 \\
\hline & \multirow{8}{*}{ Treated } & 5 & 0 & 24 & 0 & 0 & 24 \\
\hline & & 6 & 2 & 22 & 0 & 0 & 24 \\
\hline & & 7 & 3 & 21 & 0 & 0 & 24 \\
\hline & & 8 & 4 & 20 & 0 & 0 & 24 \\
\hline & & 13 & 0 & 24 & 0 & 0 & 24 \\
\hline & & 14 & 8 & 15 & 0 & 1 & 24 \\
\hline & & 15 & 3 & 21 & 0 & 0 & 24 \\
\hline & & 16 & 3 & 21 & 0 & 0 & 24 \\
\hline
\end{tabular}

Changes in Leishmania infectivity have been described long ago. Repeated in vitro passages of Leishmania lead to loss of infectivity (Giannini 1974, Nolan \& Herman 1985), although some clones were reported to remain infectious for years (Greenblatt et al. 1985, Segovia et al. 1992). It has also been noted that infectivity could be restored after passage in animals (Katakura \& Kobayashi 1985). Concerning $L$. amazonensis, the only available data report the loss of mouse infectivity of uncloned promastigotes with increasing periods of in vitro cultivation; it was related to a decreased N-glycosylation of surface proteins like gp-63 (Kink \& Chang 1988). In our case, we reduced to a minimum the time promastigotes spent outside animals, usually six to seven weeks from lesion amastigote extraction to footpad infection, comprising promastigote differentiation, subcloning and amplification of the subclones. We standardised the infection procedure by using the same amount (five million) of promastigotes of the same age (five-day stationary phase). We also cultivated the parental strain in parallel during the cloning process such that it spent the same period of time in in vitro cultures as the subclones; in spite of these precautions, there was a certain variability in the lesion growth rate of the parental strain from an experiment to another, possibly due to different growth rates of infectious and non-infectious cells within the mixture, as suggested by other authors (Kink \& Chang 1988); however, these variations appeared small compared to the differences between fast- and slow-growing subclones.

In order to tag subclones and be able to recognise their cell members within mixtures, we used cells transfected with unique cosmid episomes. This method is, however, limited for at least two reasons.
Firstly, maintaining $100 \%$ episomes inside Leishmania cells requires a selection pressure, in our case G-418. Without antibiotic, episomes are progressively lost in cultures and disappear after five to six months (unpublished observations). Since G-418-resistant mice (that could be fed with G-418) could not be found, we quantified episomal loss from transfected Leishmania cells that contained a small (pTEX vector) or a large (a random cosmid) episome. Two months after infection, amastigotes were recovered from mature lesions and spread onto agarose plates with or without G-418: we found that no more than $50 \%$ of the parasites had lost the episome, i.e., could not grow promastigote colonies on G-418 plates compared to control plates (unpublished observations). We considered it was sufficient to interpret results.

Secondly, cosmids contain genomic DNA and genes that could interfere with infectivity. We found predominant cosmids in lesions, and it is possible that they harbored genes that increased the ability of $L$. amazonensis to cause lesions. However, at least for the cosmids we tested, it was not the case. Different clones containing the in vivo predominant T3, T5, T8 or in vitro predominant $\mathrm{T} 15$ cosmids displayed different lesion growth rates, showing that these cosmids did not provide an advantage in inducing lesions. This of course cannot be generalised and should be tested systematically.

Our data are compatible with the idea that L. amazonensis cell populations consist of a mixture of different cells with different growing abilities in lesions. In vivo growth allowed the most infective ones (the founding cells) to produce lesions. Concomitantly, amastigotes developed different growing potentialities, so that a new diversity of phenotypes was created. 
We also observed that in vitro cultivation of promastigotes was not neutral. Cosmid T15 was predominant in 4-month-old in vitro promastigote cultures, while it was not enriched in lesion amastigotes, probably because it was not inside a fast-growing amastigote subclone, or it was not helping for lesion development and was lost (or remained rare) as most of the other cosmids. Why did it become predominant in the promastigote mixture? There are several possibilities: (i) contrary to its amastigote stage, the particular subclone that contained this cosmid grew faster in in vitro culture in its promastigote form than the others, which were progressively eliminated from passage to passage, or (ii) the presence of the cosmid (i.e., of some genes) gave a growth advantage to the parasites in culture medium. Thus, in vitro cultivation of parasites has consequences on the cell population that is kept in culture: only some parasites grow well and tend to predominate; this was to be suspected, but we provide here the beginning of an evidence for this phenomenon. The infectivity changes reported in long-term in vitro cultivation could be interpreted as resulting from the selection of a clonal population which grew well in culture, whether infectious or not. The biological significance of these in vitro changes may be questioned since long-term promastigote cultivation has no real equivalent in natural conditions.

Finally, what has been called infectivity recovery after passage in animals of attenuated parasites (Katakura \& Kobayashi 1985) could result from in vivo selection of rare infectious cells. A Leishmania cell should be considered as a member of a population with potential phenotypes, rather than an entity with fixed and well-defined characters, and it is the survival of the population, and not of individual cells, that is at stake. As a result, these organisms succeed very well and adapt quickly to rather different natural or artificial environmental conditions.

\section{ACKNOWLEDGEMENTS}

To Dr J-C Antoine (deceased in 2005), for his constant help and encouragements; Drs F Bringaud, N Biteau, N Courret, P Myler, M Pagès, C Ravel, Y Sterkers, K Stuart, E Tetaud and L Touratier; Profs P Bastien, J-P Dedet and M Deniau, and Mrs C Giroud, for their help and useful discussions; Dr $\mathrm{J}$ Kelly, for providing the pTEX and pcosTL vectors, and Mrs A Lagrange (Specia), for the gift of some Glucantime ${ }^{\mathrm{TM}}$. This work was done in the laboratory of Prof T Baltz (CNRS UMR 1637, then UPRESA 5016, then UMR 5162) at the Universite de Bordeaux 2 (France), and at the Laboratorio de Imunoparasitologia, Fiocruz, Salvador (Bahia, Brazil).

\section{REFERENCES}

Almeida RP, Barral-Netto M, de Jesus AMR, de Freitas LAR, Carvalho EM, Barral A. Biological behavior of Leishmania amazonensis isolated from humans with cutaneous, mucosal, or visceral leishmaniasis in BALB/c mice. Am J Trop Med Hyg. 1996; 54(2): 178-84.

Ausubel FM, Brent R, Kingston RE, Moore DD, Seidman JG, Smith JA, et al. Large scale preparation of plasmid DNA (alternate protocol). Curr Protocol Mol Biol. 1989; Suppl. 8: 1.7.

Bhattacharyya A, Mukherjee M, Duttagupta S. Studies on stibanate unresponsive isolates of Leishmania donovani. J Biosci. 2002; 27(5): 503-8.
Carrio J, de Colmenares M, Riera C, Gallego M, Arboix M, Portus M. Leishmania infantum: stage-specific activity of pentavalent antimony related with the assay conditions. Exp Parasitol. 2000; 95(3): 209-14.

Chang KP, Reed SG, McGwire BS, Soong L. Leishmania model for microbial virulence: the relevance of parasite multiplication and pathoantigenicity. Acta Trop. 2003; 85(3): 375-90.

Cuervo P, Cupolillo E, Nehme N, Hernández V, Saravia N, Fernandes O. Leishmania (Viannia): genetic analysis of cutaneous and mucosal strains isolated from the same patient. Exp Parasitol. 2004; 108(1-2): 59-66.

Cupolillo E, Momen H, Grimaldi Jr G. Genetic diversity in natural populations of New World Leishmania. Mem Inst Oswaldo Cruz. 1998; 93(5): 663-8.

Cuvillier A, Redon F, Antoine JC, Chardin P, DeVos T, Merlin G. LdARL-3A, a Leishmania promastigote-specific ADP-ribosylation factor-like protein, is essential for flagellum integrity. J Cell Sci. 2000; 113(11): 2065-74.

El Tai NO, El Fari M, Mauricio I, Miles MA, Oskam L, El Safi SH, et al. Leishmania donovani: intraspecific polymorphisms of Sudanese isolates revealed by PCR-based analyses and DNA sequencing. Exp Parasitol. 2001; 97(1): 35-44.

Garin YJ, Sulahian A, Pratlong F, Meneceur P, Gangneux JP, Prina E, et al. Virulence of Leishmania infantum is expressed as a clonal and dominant phenotype in experimental infections. Infect Immun. 2001; 69(12): 7365-73.

Giannini MS. Effects of promastigote growth phase, frequency of subculture, and host age on promastigote-initiated infections with Leishmania donovani in the golden hamster. J Protozool. 1974; 21(4): 521-7.

Greenblatt CL, Handman E, Mitchell GF, Battye FL, Schnur LF, Snary D. Phenotypic diversity of cloned lines of Leishmania major promastigotes. Z Parasitenkd. 1985; 71(2): 141-57.

Greenblatt CL, Schnur LF, Juster R, Sulitzeanu A. Clonal heterogeneity in populations of Leishmania major. Isr J Med Sci. 1990; 26(3): 129-35.

Handman E, Hocking RE, Mitchell GF, Spithill TW. Isolation and characterization of infective and non-infective clones of Leishmania tropica. Mol Biochem Parasitol. 1983; 7(2): 111-26.

Kahl LP, Byram JE, David JR. Leishmania (Viannia) braziliensis isolated from cutaneous and mucosal lesions of patients residing in Três Braços, Bahia, Brazil differ in virulence for the golden hamster. Trans R Soc Trop Med Hyg. 1990; 84(6): 783-4.

Katakura K, Kobayashi A. Enhancement of infectivity of Leishmania donovani promastigotes by serial mouse passages. J Parasitol. 1985; 71(3): 393-4.

Kelly JM, Das P, Tomas AM. An approach to functional complementation by introduction of large DNA fragments into Trypanosoma cruzi and Leishmania donovani using a cosmid shuttle vector. Mol Biochem Parasitol. 1994; 65(1): 51-62.

Kelly JM, Ward HM, Miles MA, Kendall G. A shuttle vector which facilitates the expression of transfected genes in Trypanosoma cruzi and Leishmania. Nucleic Acids Res. 1992; 20(15): 3963-9.

Kink JA, Chang KP. N-Glycosylation as a biochemical basis for virulence in Leishmania mexicana amazonensis. Mol Biochem Parasitol. 1988; 27(2-3): 181-90.

Lachaud L, Bourgeois N, Kuk N, Morelle C, Crobu L, Merlin G, et al. Constitutive mosaic aneuploidy is a unique genetic feature widespread in the Leishmania genus. Microbes Infect. 2014; 16(1): 61-6.

Martinez JE, Travi BL, Valencia AZ, Saravia NG. Metastatic capability of Leishmania (Viannia) panamensis and Leishmania (Viannia) guyanensis in golden hamsters. J Parasitol. 1991; 77(5): 762-8. 
Martinez JE, Valderrama L, Gama V, Leiby DA, Saravia NG. Clonal diversity in the expression and stability of the metastatic capability of Leishmania guyanensis in the golden hamster. J Parasitol. 2000; 86(4): 792-9.

Moreira ES, Anacleto C, Petrillo-Peixoto ML. Effect of glucantime on field and patient isolates of New World Leishmania: use of growth parameters of promastigotes to assess antimony susceptibility. Parasitol Res. 1998; 84(9): 720-6.

Nolan TJ, Herman R. Effects of long-term in vitro cultivation on Leishmania donovani promastigotes. J Protozool. 1985; 32(1): 70-5.

Noyes H, Chance M, Ponce C, Ponce E, Maingon R. Leishmania chagasi: genotypically similar parasites from Honduras cause both visceral and cutaneous leishmaniasis in humans. Exp Parasitol. 1997; 85(3): 264-73.

Pal S, Mandal A, Duttagupta S. Studies on stibanate resistant Leishmania donovani isolates of Indian origin. Indian J Exp Biol. 2001; 39(3): 249-54.

Sakthianandeswaren A, Foote SJ, Handman E. The role of host genetics in leishmaniasis. Trends Parasitol. 2009; 25(8): 383-91.
Schonian G, Schnur L, el Fari M, Oskam L, Kolesnikov AA, Sokolowska-Kohler W, et al. Genetic heterogeneity in the species Leishmania tropica revealed by different PCR-based methods. Trans R Soc Trop Med Hyg. 2001; 95(2): 217-24.

Segovia M, Artero JM, Mellado E, Chance ML. Effects of long-term in vitro cultivation on the virulence of cloned lines of Leishmania major promastigotes. Ann Trop Med Parasitol. 1992; 86(4): 347-54.

Sinagra A, Riarte A, Luna C, Campanini A, Segura EL. Leishmania (Viannia) braziliensis: biological behavior in golden hamsters of isolates from Argentine patients. Am J Trop Med Hyg. 1997; 57(1): 115-8.

Sulahian A, Garin YJF, Pratlong F, Dedet JP, Derouin F. Experimental pathogenicity of viscerotropic and dermotropic isolates of Leishmania infantum from immunocompromised and immunocompetent patients in a murine model. FEMS Immunol Med Microbiol. 1997; 17(3): 131-8.

Victoir K, Dujardin JC. How to succeed in parasitic life without sex? Asking Leishmania. Trends Parasitol. 2002; 18(2): 81-5. 